\title{
Experimental Study of Wave Attenuation for a Tandem Breakwater
}

\author{
Nur Aini Mohd Arish, Othman A. Karim, Wan Hanna Melini Wan Mohtar
}

\begin{abstract}
This paper experimentally investigates the wave attenuation of a tandem breakwater. Tandem breakwater is conventional rubble mound breakwater sheltered with a seaward-submerged structure. The experimental works were done in a wave basin with dimensions of $25 \mathrm{~m}$ length, $18 \mathrm{~m}$ width and $1.2 \mathrm{~m}$ height. All tests were performed with regular waves generated from a piston type multi element wave maker with wave height, $H=0.15,0.18$ and $0.20 \mathrm{~m}$ and wave period, $\mathrm{T}=\mathbf{2 . 0 5}, 2.20$ and $2.50 \mathrm{sec}$. Wave gauge was positioned at eight different locations to record water level and by using the measured data, the wave attenuation, WHA was calculated (WHA = 1- Kt). The objective of the experiment was to study the wave attenuation for the tandem breakwater with the influence of various angle of wave attack, $0,15,30$ and 60 degree. Apart from the influence of angle of wave attack, the influence of relative distance between submerged and rubble mound breakwater towards wave attenuation, WHA was also been investigated. Tests are done for various breakwater spacing, $(\mathrm{X} / \mathrm{d}=\mathbf{8 . 3 3 - 1 5 . 5 6 )}$ and relative heights $(\mathrm{h} / \mathrm{d}=\mathbf{0 . 4 2 - 0 . 5 6})$. The results achieved shows that WHA are increasing along with the increasing of angle of wave attack but it is vice versa with increasing of the water depth. The highest WHA is 48.46 percent and 55.02 percent for relative distance, $X / d=6.67-8.89$ $(4 \mathrm{~m})$ and $X / \mathrm{d}=10.0-13.33(6 \mathrm{~m})$ respectively, both at the condition of $60^{\circ}$ angle of wave attack.
\end{abstract}

Index Terms - tandem breakwater, wave attack, wave height attenuation, wave transmission.

\section{INTRODUCTION}

Over years, breakwater has known as a coastal defensive structure, which are built to protect ports and harbours from wave attack, to maintain a calm condition and as a safeguard to beaches. Submerged breakwaters are becoming a popular option for coastal protection is because of their low aesthetic effect on the natural environment [1]. Tandem breakwater is a combination of main conventional rubble mound breakwater and submerged structure in front of it. The unique of this combination of breakwater is that most of the wave energy is dissipated and wave intensity is reduced by the submerged structure .The submerged structure effectively trips the steeper waves and dissipates a major portion of the wave energy. Smaller waves will develop and interact with the

Nur Aini Mohd Arish, Department of Civil Engineering Technology,

Faculty of Engineering Technology, Universiti Tun Hussein Onn Malaysia. Othman A. Karim, Department of Civil and Structural Engineering,

Faculty of Engineering and Built Environment, Universiti Kebangsaan Malaysia.

Wan Hanna Melini Wan Mohtar, Department of Civil and Structural Engineering, Faculty of Engineering and Built Environment, Universiti Kebangsaan Malaysia. main breakwater and ensure its stability [2], [3]. One of the main aspect in measuring the performance of submerged breakwater is the transmission coefficient. The wave transmission coefficient, $K_{t}$ is defined as the ratio of the transmitted wave height $\left(H_{t}\right)$ at the leeside to the incident wave height $\left(H_{i}\right)$ at the breakwater seaward ([4]:

$$
K_{t}=\frac{H_{t}}{H_{i}}
$$

Common parameters that influence the value of the wave transmission coefficient are the crest width of the breakwater $(B)$, the height of the structure $\left(h_{c}\right)$, the slope of the submerged structure $(m)$, the nominal rock diameter of the armour slope $\left(D_{n 50}\right)$, the freeboard $\left(R_{c}\right)$, the water depth $(h)$, the incident significant wave height $\left(H_{i}\right)$, the wave period $(T)$ and the wave steepness $(s)[5]-[8]$. Figure 1 gives a graphical representation of these parameters.

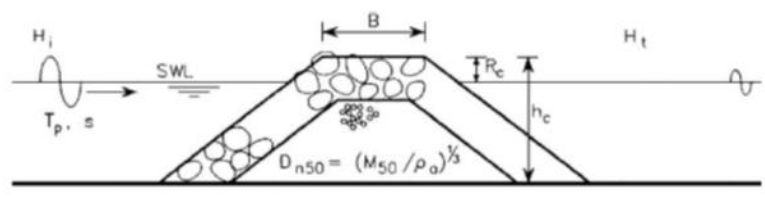

Figure 1: Parameters effecting the value of the transmission coefficient [9].

When the value of $K_{t}$ is approaching 0 , its indicate that there is no transmission occurred due to the impermeable or high breakwaters. If there is no reduction in wave height, the $K_{t}$ will be 1 ([10]. Wave height attenuation (WHA) can be expressed as $\left(1-K_{t}\right) \times 100[2]$.

\section{LITERATURE REVIEW}

One of the earliest application of tandem breakwater is by Cox and Clark [11]. A breakwater defenced by seaward-submerged reef structure has been constructed for protecting a marina harbour. They applied the relative breakwater spacing $(X / d)$ ranging from 3.49 to 5.81. A series of test was done and maximum wave height attenuation of $32 \%$ was resulted. Another research was conducted by applying tandem breakwater concept[2], [12]. The study used breakwater spacing $(X / d)$ ranging from 3.33 to 4.29 and resulted a maximum of $25 \%$ wave height attenuation. Shirlal et. al. [13] conducted study for $(X / d=2.5-13.33)$ and for different relative heights $(h / d=0.625-0.833)$ and relative widths $(B / d=0.25-1.33)$ of the submerged structure. It was observed that with $(B / d)=0.6-0.75$ constructed and relative distance $(X / d)$ of $6.25-8.33$ breaks all the incoming waves and dissipates energy and protects the breakwater optimally.

Most of the studies involving wave transmission are using 2D flume and this only focus on wave that is perpendicular to the structure in the flume[8]. It was found that the values of 
wave transmission $K_{t}$ are decreasing when there is an increase of incident angle of wave attack [14], [15]. For this paper, a study was done to measure the wave height attenuation for a tandem breakwater system with the influence of various wave attack that is not perpendicular to the structure.

\section{MATERIALS AND METHODS}

The experiments are carried out in a wave basin at the National Hydraulic Research Institute of Malaysia (NAHRIM). The wave basin consists of a conventional rubble mound breakwater and submerged breakwater as shown in Figure 2. The wave basin is $25 \mathrm{~m}$ long, $18 \mathrm{~m}$ wide and $1.2 \mathrm{~m}$ deep. Figure 3 shows the location of the wave gauges for the measurement of the incident and transmitted wave, a wave generator at one end and a wave absorber at the other. The conventional breakwater is constructed on the flat bed of the wave basin with a model scale 1:20. The submerged breakwater is built with crest width 0.3 and at location $4 \mathrm{~m}$ and $6 \mathrm{~m}$ seaward of the conventional breakwater. The tandem breakwater model is tested for wave heights of $0.15 \mathrm{~m}, 0.18 \mathrm{~m}$ and $0.20 \mathrm{~m}$ in water depths of $0.45,0.50$, and $0.60 \mathrm{~m}$. Regular waves with various heights, water depth and of periods $2.05 \mathrm{~s}$ to $2.50 \mathrm{~s} \mathrm{~m}$ can be generated with this facility. Table 1-4 details out the characteristic values for the conventional and submerged breakwater used in the tandem breakwater system.

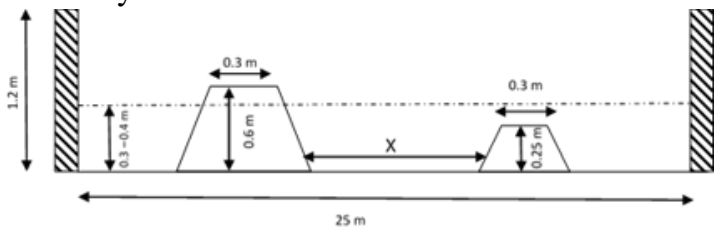

Figure 2: Side view plan of the tandem breakwater system

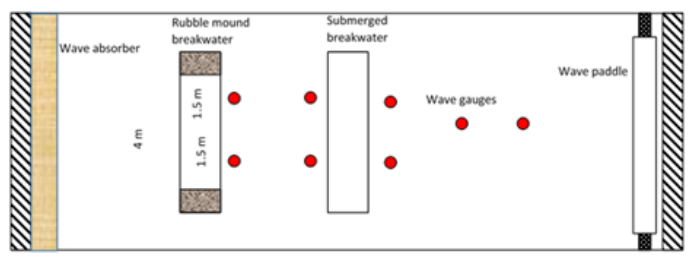

Figure 3: The arrangement of the wave gauge in the wave basin

Table 1: Wave characteristics

\begin{tabular}{|c|c|}
\hline Characteristics & Value \\
\hline Wave height, $H$ & $\begin{array}{c}0.15 \mathrm{~m}, 0.18 \mathrm{~m} \text { and } \\
0.20 \mathrm{~m}\end{array}$ \\
\hline Wave period, $T$ & $2.05 \mathrm{~s}, 2.20 \mathrm{~s}$ and $2.50 \mathrm{~s}$ \\
\hline $\begin{array}{c}\text { Number of waves, } \\
N \text { of wave }\end{array}$ & $0^{\circ}, 15^{\circ}, 30^{\circ}$ dan $60^{\circ}$ \\
\hline $\begin{array}{c}\text { Angle waves } \\
\text { attack, } \theta\end{array}$ & $0.45 \mathrm{~m}, 0.50 \mathrm{~m}$ and \\
\hline Water depth, $d$ & $0.60 \mathrm{~m}$ \\
\hline
\end{tabular}

Table 2: Characteristics for conventional breakwater model

\begin{tabular}{|l|l|}
\hline Characteristics & Value \\
\hline Model scale & $1: 20$ \\
\hline Height & $H=0.70 \mathrm{~m}$ \\
\hline Crest width & $B=0.30 \mathrm{~m}$ \\
\hline Length & $L=4 \mathrm{~m}$ \\
\hline Slope ratio & $1: 2$ \\
\hline Armour layer & Quarry stone \\
& and mortar \\
& cube \\
\hline Nominal diameter, & $0.050 \mathrm{~m}-$ Stone \\
$D_{n 50} / D_{n}$ & $0.049 \mathrm{~m}-$ Cube \\
& \\
\hline Weight, $W_{50}$ & $270-300$ gm - \\
& Stone \\
& 282 gm - Cube \\
\hline
\end{tabular}

Table 3: Characteristics for submerged breakwater model

\begin{tabular}{|l|l|}
\hline Characteristics & Value \\
\hline Model scale & $1: 20$ \\
\hline Height & $h=0.25 \mathrm{~m}$ \\
\hline Crest width & $B=0.30 \mathrm{~m}$ \\
\hline Length & $L=4 \mathrm{~m}$ \\
\hline Side slope & $1: 2$ \\
\hline Material & Quarry stones \\
\hline $\begin{array}{l}\text { Nominal diameter, } \\
D_{n 50}\end{array}$ & $0.03 \mathrm{~m}$ \\
\hline Weight, $\mathrm{W}_{50}$ & $150-200$ gm \\
\hline Porosity & 0.45 \\
\hline $\begin{array}{l}\text { Distance between } \\
\text { conventional } \\
\text { breakwater and } \\
\text { submerged } \\
\text { breakwater, } X\end{array}$ & $4.0 \mathrm{~m}$ and $6.0 \mathrm{~m}$ \\
\hline
\end{tabular}

Table 4: Dimensionless parameter for wave and submerged breakwater

\begin{tabular}{|c|l|}
\hline Characteristics & Value \\
\hline Relative height, $h / d$ & $0.42-0.56$ \\
Relative width, $B / d$ & $0.5-0.67$ \\
\hline Relative submergence, & $1.00-2.33$ \\
$F / H i$ & \\
\hline Relative distance, $X / d$ & $8.33-15.56$ \\
Wave steepness, $H / g T^{2}$ & $0.0024-0.00$ \\
\hline Relative depth, $d / g T^{2}$ & 44 \\
\hline & 5 \\
\hline
\end{tabular}

\section{RESULTS AND DISCUSSION}

\section{A. Influence of relative depth, $d / g T^{2}$ on wave height attenuation, WHA}

Figure 4 indicated that as relative depth, $d / g T^{2}$ increases, the wave height attenuation is decreasing. This is because when water depth increases, the submergence of structure increases and this reduces wave breaking resulting in increased 
transmission. The figure shows the variation of wave height attenuation, WHA with the deep-water wave steepness parameter, $H / g T^{2}$ for different relative depth, $d / g T^{2}$ for the condition of $0^{\circ}$ wave angle. The maximum wave height attenuation, WHA attained are $24.5 \%$ for 0.00734-0.01092(0.45m) $20.7 \%$

$0.00816-0.01213(0.50 \mathrm{~m}) \quad$ and $\quad 10.4 \%$

0.00979-0.01455(0.60 m), respectively.

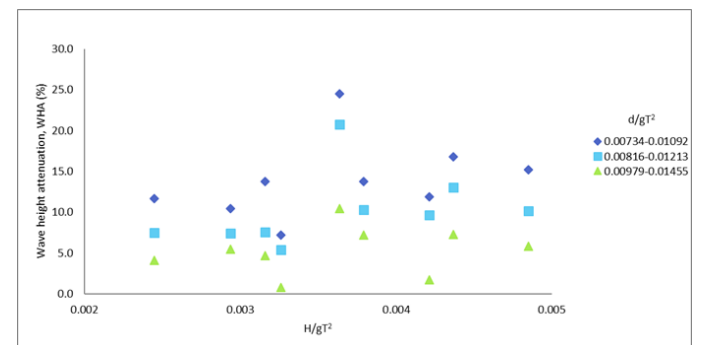

Figure 4: Wave height attenuation, $W H A$ for different relative depth, $d / g T^{2}$

\section{B. Influence of relative distance, $X / d$ on wave height} attenuation, WHA.

The comparison value of wave height attenuation, WHA between relative distance, $X / d=6.67-8.89(4 \mathrm{~m})$ and $10.0-13.33(6 \mathrm{~m})$ are shown in Figure 5. It is observed that $W H A$ for the $X / d=10.0-13.33(6 \mathrm{~m})$ are higher than $X / d$ 6.67-8.89 $(4 \mathrm{~m})$. As the distance between breakwaters $(X)$ increases, the waves that break over the submerged breakwater, loose some more energy while propagating in the energy dissipation zone and causing higher wave energy dissipation. Results show that for $X / d=6.67-8.89(4 \mathrm{~m})$ with relative depth, $d / g T^{2}=0.00734-0.01092(0.45 \mathrm{~m})$ the wave height attenuation (WHA) is 24.5 percent (maximum) while for $10.0-13.33(6 \mathrm{~m})$ the WHA is 42.0 percent (maximum) with the same relative depth. Research by [13] found out that with $X / d=2.5-3.33$, it attenuates the waves by a maximum amount of $18 \%, X / d=6.25-8.33$ at about $33 \%$ and for $X / d=$ $10-13.33$ at about $43 \%$.

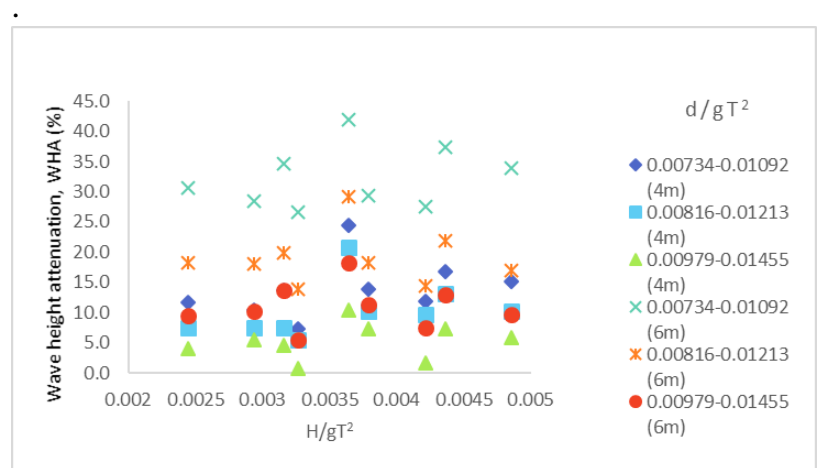

Figure 5: Wave height attenuation, $W H A$ for relative distance, $X / d$ 6.67-8.89(4 m) and 10.0-13.33(6 m)

\section{Influence of angle of wave attack, $\theta$ on wave height attenuation, WHA}

Figures 6 and 7 shows the value of WHA for relative distance, $X / d=6.67-8.89(4 \mathrm{~m})$ with the influence of angle of wave attack, $\theta$. For the maximum relative depth, $d / g T^{2}=$
0.008904-0.013163(0.60 m) as in Figure 6, the wave height attenuation is increasing with the angle of wave attack, $\theta$. The same trend of graph can be seen for the minimum relative depth, $d / g T^{2} 0.006678-0.009872(0.45 \mathrm{~m})$. The highest $W H A$ is 28.15 percent and 48.46 percent for depth of $0.60 \mathrm{~m}$ and $0.45 \mathrm{~m}$ respectively, both at the condition of $60^{\circ}$ angle of wave attack. Table 5 details out the $W H A$ for every water depth for $X / d=6.67-8.89(4 \mathrm{~m})$.

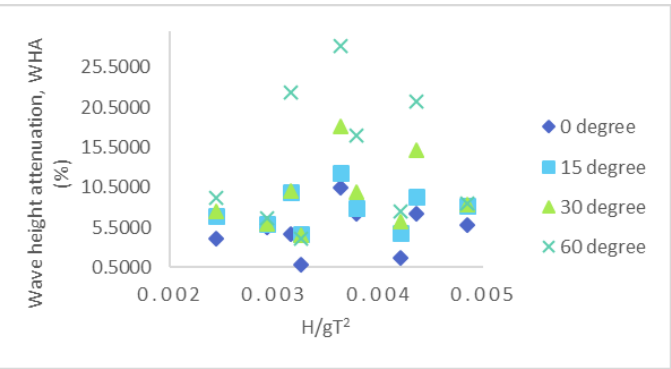

Figure 6: Location of submerged breakwater, $X / d=$ 6.67-8.89 $(4 \mathrm{~m})$, depth $=0.6 \mathrm{~m}$

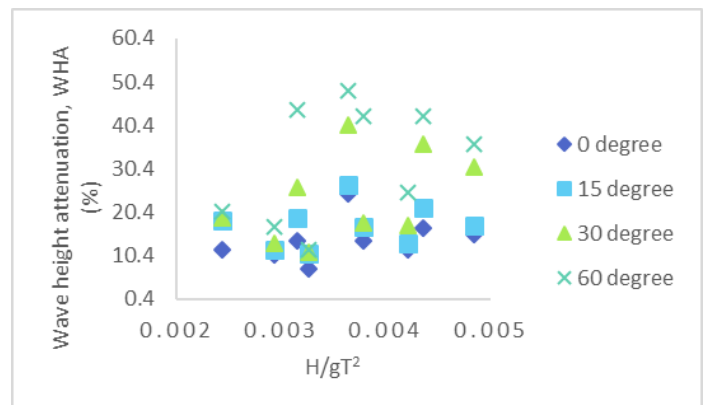

Figure 7: Location of submerged breakwater, $X / d=$ 6.67-8.89 $(4 \mathrm{~m})$, depth $=0.45 \mathrm{~m}$

Table 5: Wave height attenuation for relative distance,

\begin{tabular}{|c|c|c|c|c|}
\hline \multicolumn{5}{|c|}{$X / d=6.67-8.89(4 \mathrm{~m})$} \\
\hline & \multicolumn{4}{|c|}{$\begin{array}{l}\text { Wave height attenuation } \\
(W H A)(\%)\end{array}$} \\
\hline$d / g T^{2}$ & $0^{\circ}$ & $15^{\circ}$ & $30^{\circ}$ & $60^{\circ}$ \\
\hline 0.00734-0.010 & 24. & 26.6 & 40.5 & 48. \\
\hline $92(0.45 \mathrm{~m})$ & 49 & 3 & 1 & 46 \\
\hline 0.00816-0.012 & & & & \\
\hline \multirow{4}{*}{$\begin{array}{l}13(0.50 \mathrm{~m}) \\
0.00979-0.014 \\
55(0.60 \mathrm{~m})\end{array}$} & 20. & 23.7 & 32.0 & 45. \\
\hline & 73 & 5 & 5 & 73 \\
\hline & 10 & 120 & 101 & 20 \\
\hline & 43 & 7 & $2^{10.1}$ & 15 \\
\hline
\end{tabular}

The same pattern of graph also can be seen for $X / d=$ $10.0-13.33(6 \mathrm{~m})$. All the graphs indicate the increasing value of WHA when the angle of wave attack, $\theta$ are increasing from $0^{\circ}$ to $60^{\circ}$. Figures 8 and 9 represents the graphs for the maximum relative depth, $d / g T^{2}=0.008904-0.013163(0.60$ $\mathrm{m})$ and minimum relative depth, $d / g T^{2}$ 0.006678-0.009872(0.45 $\mathrm{m})$ respectively. 


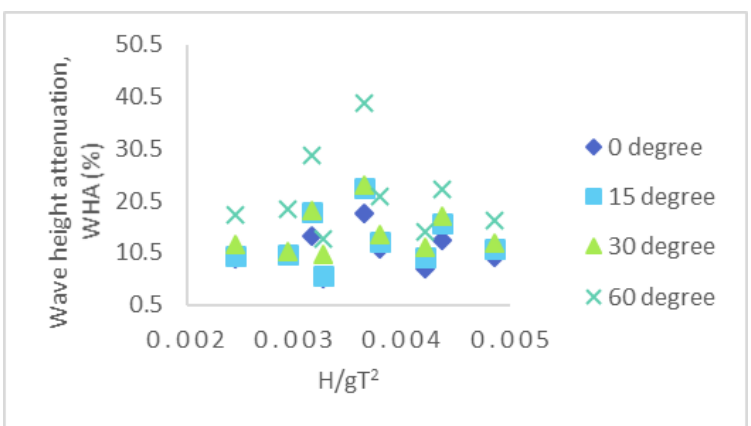

Figure 8: Location of submerged breakwater, $X / d=$ 10.0-13.3 (6 m), depth $=0.6 \mathrm{~m}$

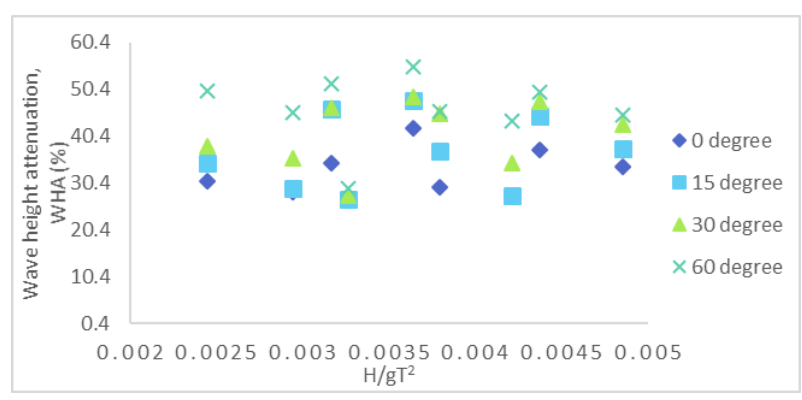

Figure 9: Location of submerged breakwater, $X / d=$ 10.0-13.3 $(6 \mathrm{~m})$, depth $=0.45 \mathrm{~m}$

Table 6 shows the detail results of WHA for relative distance, $X / d=10.0-13.3(6 \mathrm{~m})$. It shows that $W H A$ are increasing along with the increasing of angle of wave attack but it is decreasing with increasing of water depth. The highest $W H A$ is for the depth of $0.45 \mathrm{~m}$ and at the angle of $60^{\circ}$, which is $55.02 \%$. The lowest WHA can be seen at the angle of $0^{\circ}$ where the value is 18.19 percent.

Table 6: Wave height attenuation for relative distance, $X / d=10.0-13.33(6 \mathrm{~m})$

\begin{tabular}{|l|l|l|l|l|}
\hline & \multicolumn{4}{|c|}{ Wave height attenuation (WHA) (\%) } \\
\hline $\boldsymbol{d} / \boldsymbol{g} \boldsymbol{T}^{\mathbf{2}}$ & $0^{\circ}$ & $15^{\circ}$ & $30^{\circ}$ & $60^{\circ}$ \\
\hline $\begin{array}{l}\mathbf{0 . 0 0 7 3 4 - 0 . 0 1 0 9 2} \\
(\mathbf{0 . 4 5 m})\end{array}$ & 42.00 & 47.89 & 48.60 & 55.02 \\
$\begin{array}{l}\mathbf{0 . 0 0 8 1 6 - 0 . 0 1 2 1 3} \\
(\mathbf{0 . 5 0 m})\end{array}$ & 29.24 & 29.98 & 34.82 & 45.16 \\
$\begin{array}{l}\mathbf{0 . 0 0 9 7 9 - 0 . 0 1 4 5 5} \\
(\mathbf{0 . 6 0 m})\end{array}$ & 18.19 & 22.91 & 23.43 & 39.21 \\
\hline
\end{tabular}

\section{CONCLUSION}

Following are the conclusions drawn from the present study:

1. As relative depth, $d / g T^{2}$ increases, the wave height attenuation is decreasing. The highest WHA is 28.15 percent and 48.46 percent for depth of $0.60 \mathrm{~m}$ and $0.45 \mathrm{~m}$ respectively, for the condition of $60^{\circ}$ angle of wave attack.

2. It is observed that $W H A$ for the $X / d=10.0-13.33(6 \mathrm{~m})$ are higher than $X / d 6.67-8.89(4 \mathrm{~m})$. For $X / d=$ $6.67-8.89(4 \mathrm{~m})$ with relative depth, $d / g T^{2}=$ $0.00734-0.01092(0.45 \mathrm{~m})$ the wave height attenuation (WHA) is $24.5 \%$ (maximum) while for $10.0-13.33(6 \mathrm{~m})$ the WHA is $42.0 \%$ (maximum) with the same relative depth.
3. WHA are increasing along with the increasing of angle of wave attack. For relative distance, $X / d=$ $6.67-8.89(4 \mathrm{~m})$ the $W H A$ for $0.45 \mathrm{~m}$ depth is 24.49 for $0^{\circ}$ wave attack and $48.46 \%$ for $60^{\circ}$ wave attack

The authors are appreciative to the National Hydraulic Research Institute of Malaysia (NAHRIM) for the facilities provided for the study and permission granted to publish the results.

\section{REFERENCES}

[1] R. Ranasinghe, M. Larson, and J. Savioli, "Shoreline response to a single shore-parallel submerged breakwater," Coast. Eng., 2010.

[2] K. G. Shirlal \& Subba Rao M.ISH, "Laboratory Studies on the Stability of Tandem Breakwater," ISH J. Hydraul. Eng., vol. 9, no. 1, pp. 36-45, 2003.

[3] J. J. S, G. Kuntoji, S. Rao, and P. Student, "Prediction of Transmitted Wave Height of Tandem Breakwater using Support Vector Regression,” Int. J. Innov. Res. Sci. Eng. Technol. (An ISO Certif. Organ., vol. 3297, no. 9, 2007.

[4] J. van der Meer and I. F. R. Daemen, Stability and Wave Transmission at Low-Crested Rubble-Mound Structures, vol. 120. 1994.

[5] J. W. van der Meer and I. F. R. Daemen, "Stability and Wave Transmission at Low-Crested Rubble-Mound Structures," J. Waterw. Port, Coastal, Ocean Eng., 2006.

[6] C. V Makris and C. D. Memos, "Wave Transmission Over Submerged Breakwaters: Performance of Formulae And Models," The Seventeenth International Offshore and Polar Engineering Conference. International Society of Offshore and Polar Engineers, Lisbon, Portugal, 2007.

[7] I. Melito and J. Melby, Wave runup, transmission, and reflection for structures armored with CORE-LOC (R), vol. 45. 2002.

[8] J. W. Van Der Van der Meer, B. Wang, A. Wolters, B. Zanuttigh, and M. Kramer, "Oblique wave transmission over low crested structures," in 4th International coastal structures conference, 2004, pp. 567-579.

[9] J. W. van der Meer, R. Briganti, B. Zanuttigh, and B. Wang, "Wave transmission and reflection at low-crested structures: Design formulae, oblique wave attack and spectral change," Coast. Eng., vol. 52, no. 10-11, pp. 915-929, 2005.

[10] D. I. Yuliastuti and A. M. Hashim, "Wave Transmission on Submerged Rubble Mound Breakwater Using L-Blocks," vol. 6, pp. 243-248, 2011.

[11] J. C. Cox and G. R. Clark, "6. Design development of a tandem breakwater system for Hammond Indiana," in Coastal structures and breakwaters, Thomas Telford Publishing, 1992, pp. 111-121.

[12] K. G. Shirlal, S. Rao, V. Ganesh, and Manu, "Stability of breakwater defenced by a seaward submerged reef," Ocean Eng., 2006.

[13] K. G. Shirlal, S. Rao, V. Ganesh, and Manu, "Stability of breakwater defenced by a seaward submerged reef," Ocean Eng., vol. 33, no. 5-6, pp. 829-846, 2006.

[14] van der Meer J.W., Briganti R., B. Wang, and B. Zanuttigh, "Wave transmission at low-crested structures, including oblique wave attack," Proc. 29th Int. Conf. Coast. Eng. ASCE, vol. 41, pp. 52-64, 2004.

[15] B. Wang, A. K. Otta, and A. J. Chadwick, "Transmission of obliquely incident waves at low-crested breakwaters: Theoretical interpretations of experimental observations," Coast. Eng., vol. 54, no. 4, pp. 333-344, 2007. 